\title{
OPEM
}

www.opem.org

Oriental Pharmacy and Experimental Medicine 2008 7(5), 527-533

DOI 10.3742/OPEM.2008.7.5.527

\section{Analgesic and anti-inflammatory effect of the aqueous extract of root of Angelica Dahurica}

\author{
In-Ho Choi ${ }^{1}$, Hyung-Ho Lim ${ }^{1}$, Yun-Kyung Song ${ }^{1}$, Jin-Woo Lee ${ }^{2}$, Young-Sick Kim ${ }^{2}$, Il-Gyu Ko ${ }^{2}$, \\ Ki-Jeong Kim ${ }^{2}$, Mal-Soon Shin ${ }^{2}$, Khae-Hawn Kim ${ }^{3}$ and Chang-Ju Kim ${ }^{2, *}$ \\ ${ }^{1}$ Department of Rehabilitation Medicine, College of Oriental Medicine, Kyungwon University, 65 Bokjung-dong, \\ Sujung-gu, Songnam 461-701, Republic of Korea; ${ }^{2}$ Kohwang Medical Research Institute, Department of \\ Physiology, College of Medicine, Kyung Hee University, 1 Hoegi-Dong, Dongdaemun-gu, Seoul, 130-701, \\ Republic of Korea; ${ }^{3}$ Department of Urology, Gil Medical Center, Gachon University of Medicine and Science, \\ 1198 Goowhol-dong, Namdong-gu, Inchon 405-760, Republic of Korea
}

\section{SUMMARY}

\begin{abstract}
Angelica dahurica (Umbelliferae) grows in China, Japan, Russia, and Korea. The root of Angelica dahurica has been used as a traditional folk medicine to treat headache and toothache. In this study, the effects of the aqueous extract of Angelica dahurica on acetic acid-induced abdominal pain, carrageenan-induced edema, and thermal hyperalgesia were investigated using mice and rats. The present results showed that the aqueous extract of Angelica dahurica inhibited acetic acidinduced abdominal pain in mice and reduced carrageen-induced edema in rats. The present study showed that the aqueous extract of Angelica dahurica possesses anti-inflammatory and analgesic effects.
\end{abstract}

Key words: Angelica dahurica; Analgesic and anti-inflammatory effect; Edema; Thermal pain

\section{INTRODUCTION}

The aromatic medicinal plant Angelica dahurica (Umbelliferae) is a perennial herb growing to $2.5 \mathrm{~m}$ with large three-branched leaves and umbels bearing many white flower heads. It grows wild in thickets in China, Japan, Russia, and Korea. The roots of this species have been used as traditional folk medicine to treat headache, toothache, aching eyes, abdominal pain, hysteria, bleeding, menstrual disorder, and neuralgia. Several coumarins that are constituents of Angelica

*Correspondence: Chang-Ju Kim, Department of Physiology, College of Medicine, Kyung Hee University, 1 Hoigidong, Dongdaemoon-gu, Seoul 130-701, Republic of Korea. Tel: +8229610407; Fax: +8229642195; E-mail: changju@khu.ac.kr dahurica have been extensively studied for their chemical structures (Saiki et al., 1971; Wang et al., 2001), and pharmacological effects (Kimura et al., 1982; Kim et al., 1992; Kwon et al., 1997).

Pain is the most common symptom encountered in clinical practice. It is believed that current analgesic drugs such as opiates and non-steroidal anti-inflammatory drugs (NSAID) are not always useful in many painful conditions, because of their side effects and potency. As a result, the search for other alternatives seems necessary and beneficial.

The writhing test is a well-known animal model of inflammatory and visceral pain. It is useful in animal model studying anti-nociceptive effects. Carrageenan-induced local inflammation is a commonly used method to evaluate the 
effects of NSAID. Therefore, carrageenan-induced paw edema has been used to asses the contribution of mediators involved in vascular changes associated with acute inflammation (Di Rosa et al., 1971). Also, the plantar test using Hargreaves apparatus can determine thermal pain threshold by exposing the animals to the heat (Hargreaves et al., 1988).

In the present study, we evaluated the antinociceptive and anti-inflammatory effects of the aqueous extract of Angelica dahurica using mice and rats. For this study, several experimental pain models such as acetic acid-induced writhing response, carrageenan-induced edema, and plantar test were performed.

\section{MATERIALS AND METHODS}

\section{Preparation of the aqueous extract of Angelica dahurica}

To obtain the aqueous extract of Angelica dahurica, $50 \mathrm{~g}$ of Angelica dahurica was added to distilled water, and extraction was performed by heating at $90^{\circ} \mathrm{C}$ for $2 \mathrm{~h}$, concentrating with a rotary evaporator, and lyophilization (Eyela, Tokyo, Japan). The resulting powder, weighing $12.4 \mathrm{~g}$, was dissolved in saline solution and filtered through a $0.45 \mu \mathrm{m}$ syringe before use.

\section{Animals and treatments}

Male ICR mice weighing 28-30 g and Male Sprague-Dawley rats weighing 150 - $160 \mathrm{~g}$ were used for the experiments. The experimental procedures were performed in accordance with the animal care guidelines of the National Institutes of Health $(\mathrm{NIH})$ and the Korean Academy of Medical Sciences. The animals were housed under laboratory conditions at a controlled temperature $\left(20 \pm 2^{\circ} \mathrm{C}\right)$ and maintained under light-dark cycles, each consisting of $12 \mathrm{~h}$ of light and $12 \mathrm{~h}$ of darkness (lighting from 07:00 to 19:00 h) with food and water made available ad libitum.

\section{Acetic acid-induced writhing response in mice} The animals were divided into five groups: the control group, the acetic acid-injection group, the acetic acid-injection and $50 \mathrm{mg} / \mathrm{kg}$ Angelica dahurica-treated group, the acetic acid-injection and $100 \mathrm{mg} / \mathrm{kg}$ Angelica dahurica-treated group, and the acetic acid-injection and $200 \mathrm{mg} / \mathrm{kg}$ Angelica dahurica-treated group ( $\mathrm{n}=10$ in each group). The aqueous extract of Angelica dahurica were orally administered to the mice at $1 \mathrm{~h}$ before acetic acid injection. Mice were injected intraperitoneally with $0.15 \mathrm{ml}$ of $1.0 \%$ acetic acid as an irritant, and then placed in an individual plastic cage $(20 \times 30 \times 12 \mathrm{~cm}$ high $)$ for the observation of writhing response. The number of writhing reflex was counted for $30 \mathrm{~min}$ starting immediately after acetic acid injection.

\section{Carrageenan-induced edema in rats}

The animals were divided into five groups: the control group, the carrageenan-induced edema group, the carrageenan-induced edema and 100 $\mathrm{mg} / \mathrm{kg}$ Angelica dahurica-treated group, the carrageenan-induced edema and $200 \mathrm{mg} / \mathrm{kg}$ Angelica dahurica-treated group, and the carrageenan-induced edema and $400 \mathrm{mg} / \mathrm{kg}$ Angelica dahurica-treated group ( $\mathrm{n}=10$ in each group).

The volume of the paw edema in each animal was measured using a plethysmometer (Ugo Basile, Italy) with a precision of two decimal places. To induce edema in the experimental animals, a single subplantar injection of carrageenan (1\%, 0.05 ml; Sigma Chemical Co., St. Louis, MO, USA) was given to each animal, and the animals in the control group received injections of equivalent dose of normal saline as a same method (Sluka and Chandran, 2002).

The animals in the Angelica dahurica-treated groups received orally with $1 \mathrm{ml}$ of the aqueous extract of Angelica dahurica at the respective dose at $1 \mathrm{~h}$ before carrageenan injection, and those in the control group and in the carrageenan-induced edema group received equivalent amount of 
drinking water at $1 \mathrm{~h}$ before carrageenan injection. The paw volume was measured at 1, 2, 3, 4 and $5 \mathrm{~h}$ after carrageenan injection. The percentage of edema was calculated as follows:

Percentage of edema $(\%)=(\mathrm{Vt}-\mathrm{Vn}) / \mathrm{Vn} \times 100$

$\mathrm{Vt}=$ The paw volume of each time after the injection of carrageenan

$\mathrm{Vn}=$ The paw volume before the injection of carrageenan

The plantar test (Hargreaves's method) in rats The animals were divided into four groups: the thermal stimulation-induced nociception (control) group, the thermal stimulation-induced nociception and $50 \mathrm{mg} / \mathrm{kg}$ Angelica dahurica-treated group, the thermal stimulation-induced nociception and $100 \mathrm{mg} / \mathrm{kg}$ Angelica dahurica-treated group, and the thermal stimulation-induced nociception and $200 \mathrm{mg} / \mathrm{kg}$ Angelica dahurica-treated group ( $\mathrm{n}=6$ in each group).

To assess nociceptive response to thermal stimulus, paw withdrawal latency was measured by the method of Hargreaves et al. (1988) The

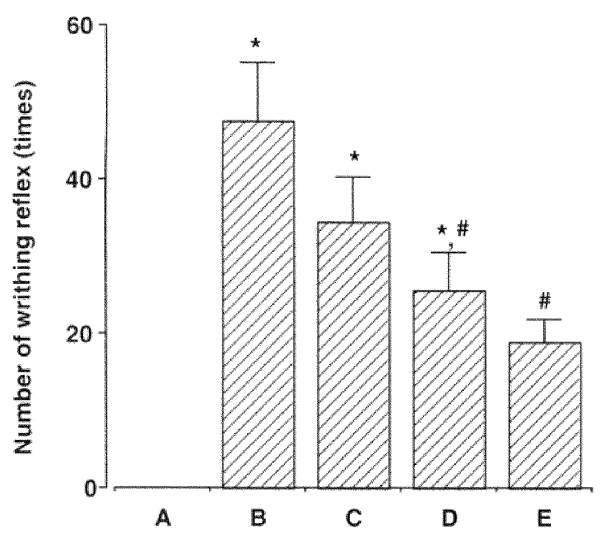

Fig. 1. Effect of Angelica dahurica on the number of writhing reflex. (A) Control group, (B) acetic acidinjection group, (C) acetic acid-injection and $50 \mathrm{mg} /$ $\mathrm{kg}$ Angelica dahurica-treated group, (D) acetic acidinjection and $100 \mathrm{mg} / \mathrm{kg}$ Angelica dahurica-treated group, (E) acetic acid-injection and $200 \mathrm{mg} / \mathrm{kg}$ Angelica dahurica-treated group. represents $P<0.05$ compared to the control group. "represents $P<0.05$ compared to the acetic acid-injection group. centre of a focused beam of radiant heat was applied to the plantar surface of the hind paw in rats, and then the withdrawal latency time was recorded. The intensity of the heat stimulus was adjusted so that the baseline latency was $6 \mathrm{~s}$, and $20 \mathrm{~s}$ cut-off time was imposed to avoid tissue damage. Three min was allowed between each test. The animals in the Angelica dahurica-treated groups received orally with $1 \mathrm{ml}$ of the aqueous extract of Angelica dahurica at the respective dose at $1 \mathrm{~h}$ before test, and those in the control group received equivalent amount of saline at $1 \mathrm{~h}$ before test. The withdrawal latency time was measured at $1 \mathrm{~h}$ and $2 \mathrm{~h}$ after drug administration.

\section{Data analysis}

Statistical analysis was performed using one-way ANOVA followed by Duncan post-hoc test. The results are presented as the mean \pm S.E.M. Difference was considered significant at $P<0.05$.

\section{RESULTS}

Effect of Angelica dahurica on acetic acid-induced writhing response in mice

The number of the writhing reflex in the control group was $00.00 \pm 0.00$. The number of writhing reflex in the acetic acid-injection group was 47.60 \pm 7.47 . The number of writhing reflex in the acetic acid-injection and Angelica dahurica $(50 \mathrm{mg} / \mathrm{kg}$, $100 \mathrm{mg} / \mathrm{kg}$, and $200 \mathrm{mg} / \mathrm{kg}$ )-treated groups was $34.44 \pm 5.74,25.57 \pm 4.83$, and $18.80 \pm 3.00$, respectively.

The present results showed that acetic acid injection into the abdominal cavity induced writhing reflex. The pre-treatment with the aqueous extract of Angelica dahurica suppressed acetic acid-induced writhing response as a dosedependently.

Effect of Angelica dahurica on the volume of carrageenan-induced paw edema in rat

After $1 \mathrm{~h}$, paw volume in the control group was 


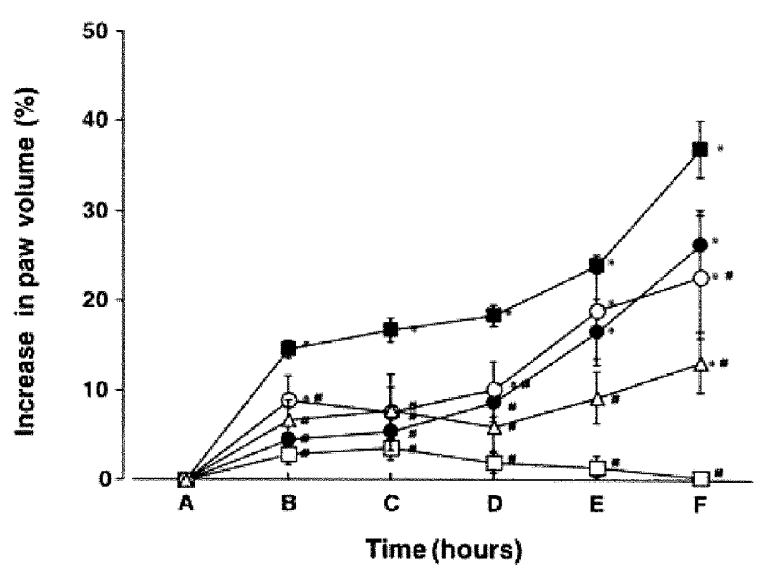

Fig. 2. Effect of Angelica dahurica on carrageenaninduced paw edema. $(\square)$ Control group, $(\square)$ carrageenaninduced edema group, $(O)$ carrageenan-induced edema and $100 \mathrm{mg} / \mathrm{kg}$ Angelica dahurica-treated group, $(\bigcirc)$ carrageenan-induced edema and $200 \mathrm{mg} / \mathrm{kg}$ Angelica dahurica-treated group, $(\triangle)$ carrageenan-induced edema and $400 \mathrm{mg} / \mathrm{kg}$ Angelica dahurica-treated group. "represents $P<0.05$ compared to the control group. \# represents $P<0.05$ compared to the carrageenaninduced edema group.

$2.87 \pm 1.16 \%$. Paw volume in the carrageenaninduced edema group was increased to $14.62 \pm$ $1.01 \%$. Paw volume in the carrageenan-induced edema and Angelica dahurica $(100 \mathrm{mg} / \mathrm{kg}, 200$ $\mathrm{mg} / \mathrm{kg}$, and $400 \mathrm{mg} / \mathrm{kg}$ )-treated groups was decreased to $4.44 \pm 0.68 \%, 8.90 \pm 2.69 \%$, and $6.71 \pm$ $2.17 \%$, respectively.

After $2 \mathrm{~h}$, paw volume in the control group was $3.58 \pm 1.37 \%$. Paw volume in the carrageenaninduced edema group was increased to $16.72 \pm 1.30 \%$. Paw volume in the carrageenan-induced edema and Angelica dahurica (at $100 \mathrm{mg} / \mathrm{kg}, 200 \mathrm{mg} / \mathrm{kg}$, and $400 \mathrm{mg} / \mathrm{kg}$ )-treated groups was decreased to $5.34 \pm 0.87 \%, 7.53 \pm 4.27$, and $7.73 \pm 2.52 \%$, respectively.

After $3 \mathrm{~h}$, paw volume in the control group was $1.94 \pm 1.14 \%$. Paw volume in the carrageenaninduced edema group was increased to $18.33 \pm$ $1.17 \%$. Paw volume in the carrageenan-induced edema and Angelica dahurica (100 mg/kg, $200 \mathrm{mg} /$ $\mathrm{kg}$, and $400 \mathrm{mg} / \mathrm{kg}$ )-treated group was decreased to $8.61 \pm 2.05 \%, 10.07 \pm 3.07 \%$, and $5.93 \pm 2.61 \%$, respectively.

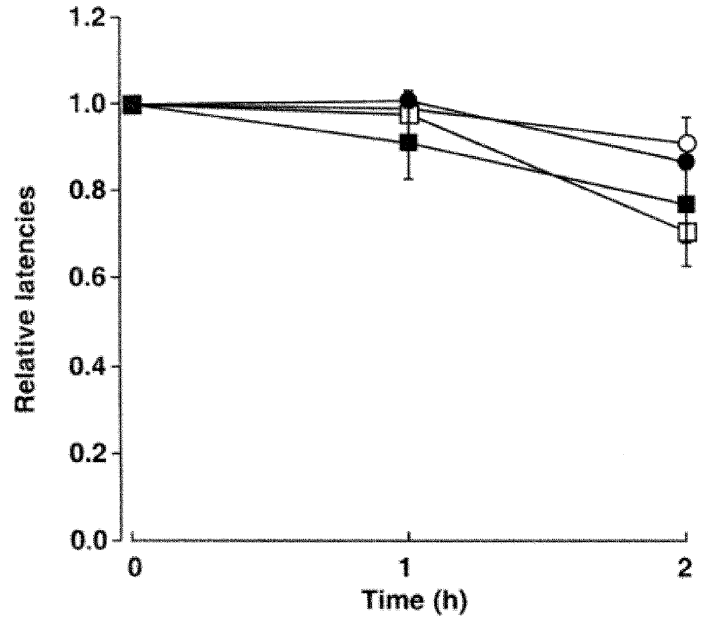

Fig. 3. Effect of Angelica dahurica on thermal pain. (O) Thermal stimulation-induced nociception group (control), ( $)$ thermal stimulation-induced nociception and $50 \mathrm{mg} / \mathrm{kg}$ Angelica dahurica-treated group, $(\square)$ thermal stimulation-induced nociception and $100 \mathrm{mg} / \mathrm{kg}$ Angelica dahurica-treated group, $(\square)$ thermal stimulationinduced nociception and $200 \mathrm{mg} / \mathrm{kg}$ Angelica dahuricatreated group.

After $4 \mathrm{~h}$, paw volume in the control group was $1.47 \pm 1.17 \%$. Paw volume in the carrageenaninduced edema group was increased to $24.07 \pm$ $0.99 \%$. Paw volume in the carrageenan-induced edema and Angelica dahurica $(100 \mathrm{mg} / \mathrm{kg}, 200 \mathrm{mg} / \mathrm{kg}$, and $400 \mathrm{mg} / \mathrm{kg}$ )-treated groups was decreased to $16.53 \pm 3.63 \%, 19.00 \pm 5.52 \%$, and $9.25 \pm 2.88 \%$, respectively.

After $5 \mathrm{~h}$, paw volume in the control group was $0.36 \pm 0.42 \%$. Paw volume in the carrageenaninduced edema group was increased to $36.97 \pm$ $3.17 \%$. Paw volume in the carrageenan-induced edema and Angelica dahurica $(100 \mathrm{mg} / \mathrm{kg}, 200$ $\mathrm{mg} / \mathrm{kg}$, and $400 \mathrm{mg} / \mathrm{kg}$ )-treated groups was decreased to $26.29 \pm 3.85 \%, 22.68 \pm 6.84 \%$, and 13.19 $\pm 3.40 \%$, respectively.

The present results showed that the paw volume in the control group maintained constant level, while carrageenan injection increased paw volume as time-dependently. Pre-treatment with the aqueous extract of Angelica dahurica suppressed carrageenan-induced paw edema. 
Effect of Angelica dahurica on the plantar test (nociceptive thermal stimulation) in rats

After $1 \mathrm{~h}$, paw withdrawal threshold of the pretreated value was considered as 1.00. The withdrawal latency of thermal stimulation-induced nociception group was $0.99 \pm 0.02$. The withdrawal latency of thermal stimulation-induced nociception and Angelica dahurica $(50 \mathrm{mg} / \mathrm{kg}, 100 \mathrm{mg} / \mathrm{kg}$, and $200 \mathrm{mg} / \mathrm{kg}$ )-treated group was $1.01 \pm 0.01,0.98 \pm$ 0.05 , and $0.91 \pm 0.08$.

After $2 \mathrm{~h}$, the withdrawal latency of thermal stimulation-induced nociception group was $0.91 \pm$ 0.06 . The withdrawal latency of thermal stimulationinduced nociception and Angelica dahurica (50 $\mathrm{mg} / \mathrm{kg}, 100 \mathrm{mg} / \mathrm{kg}$, and $200 \mathrm{mg} / \mathrm{kg}$ )-treated group was $0.87 \pm 0.01,0.71 \pm 0.08$, and $0.77 \pm 0.09$.

The present results showed that the aqueous extract of Angelica dahurica exerted no significant effect on the withdrawal latency of thermal stimulation-induced nociception.

\section{DISCUSSION}

Angelica dahurica (Umbelliferae) is a perennial herb distributed in the whole area of Korea, and its root has been used as an anti-pyretic and analgesic agent. This study evaluated the scientific basis for the use of Angelica dahurica on inflammation and pain. The anti-nociceptive and anti-edematogenic effects were analysed using different stimuli, such as chemical agents (acetic acid and carrageenan) and heat (plantar test). Angelica dahurica contains several coumarins and furanocoumarins. The coumarins are known to inhibit multiplication of bacteria, fungi, and viruses (Hudson et al., 1993; Kofinas et al., 1998) and they demonstrated antiallergic (Kimura and Okuda, 1997), anti-inflammatory (Chen et al., 1995), and immune suppressive activities (Kuzel et al., 1992). The furanocoumarins also have a variety of biological properties such as inhibitory effects on prostaglandin E production (Ban et al., 2003), acetylcholinesterase (Kim et al., 2002), and nitric oxide generation (Ryu et al., 2001).
These evidences indicate that coumarins and furanocoumarins can modulate the prostanoid biosynthetic pathway. Arachdonic acid, which is accumulated in the membrane lipid, is selectively released from the phospholipids pool by chemical or mechanical stimulation, it subsequently converted to prostaglandins (PGs) by two enzymes: COX-1 and COX-2 (Griffiths, 1999). COX-2 is primarily responsible for PGs produced in inflammation while COX-1 is involved in normal homeostasis. In this regard, COX-2 is up-regulated in the air pouch and catalyzes the production of large amounts of $\mathrm{PGE}_{2}$ (Masferrer et al., 1994). The upregulation of COX-2 inducing $\mathrm{PGE}_{2}$ synthesis is a major event in acetic acid-induced writhing response and in carrageenan-induced inflammation. Alternatively, the decrease of $\mathrm{PGE}_{2}$ is induced by inhibition of the release of tumor necrosis factor- $\alpha$ (TNF- $\alpha$ ), because stimulation of macrophages/ monocytes, fibroblasts, and epithelial cells with cytokines such as interleukin-1 (IL-1) and TNF- $\alpha$ increases $\mathrm{PGE}_{2}$ production (Griffiths, 1999).

In the present study, the analgesic effect of Angelica dahurica was evaluated by acetic acidinduced writhing response. The acetic acid-induced abdominal writhing which is the visceral pain model. Releases of arachidonic acid via cyclooxygenase induces prostaglandin biosynthesis, and it plays a role in the nociceptive mechanism (Franzotti et al., 2000). The results of the present study showed that the mice pre-treated with the aqueous extract of Angelica dahurica revealed a dose-dependent analgesic effect on acetic acid-induced writhing response and this effect may be due to inhibition of the synthesis of the arachidonic acid metabolites.

The carrageenan test was selected in this study, because of its sensitivity in detecting acute phase of inflammatory response (Di Rosa et al., 1971). The intraplantar injection of carrageenan in rats induces paw edema. Its first phase $(0-2.5 \mathrm{~h}$ after injection of carrageenan) was resulted from the increase of vascular permeability and concomitant release of mediators such as histamine, serotonin, 
and kinins. The second phase is correlated with the production of PGs, oxygen-derived free radicals, and enhancing of COX-2 activity (Panthong et al., 2004). In the present results, administration of the aqueous extract of Angelica dahurica suppressed the edematous response at $2 \mathrm{~h}$ after carrgeenan injection and this effect continued up to $5 \mathrm{~h}$.

Thermal hyperalgesia can be explained by central convergence of afferents from the deep tissues and skin (Light et al., 2003). Central sensitization and inhibition can be evaluated by administration of agonists such as morphine, which preferentially attenuates in put to the spinal cord from C nociceptors (Cooper et al., 1986). Slow temporal summation of pain depends upon $\mathrm{N}$-methyl-D-aspartate receptor activation by $C$ nociceptor input (Vierck et al., 1997). In the present results, however, the aqueous extract of Angelica dahurica did not preferentially attenuate pain sensitivity.

Here in this study, we demonstrated that the aqueous extract of Angelica dahurica has antinociceptive and anti-inflammatory activities, and it is possible that this herb can be wide used to treat inflammation and pain. Further studies are needed to elucidate the mechanisms behind these effects of this herb.

\section{ACKNOWLEDGEMENTS}

This study was supported by a grant of Oriental Medicine R\&D Project, Ministry of Health\& Welfare, Republic of Korea. (0405-OD00-0815-B050049)

\section{REFERENCES}

Ban HS, Lim SS, Suzuki K, Jung SH, Lee S, Lee YS, Shin KH, Ohuchi K. (2003) Inhibitory effects of furanocoumarins isolated from the roots of Angelica dahuricaon prostaglandin $\mathrm{E}_{2}$ production. Planta Med. 69, 408-412.

Chen YF, Tsai HY, Wu TS. (1995) Anti-inflammatory and analgesic activities from roots of Angelica pubescens. Planta Med. 61, 2-8.

Cooper BY, Vierck Jr CJ, Yeomans DC. (1986) Selective reduction of second pain sensations by systemic morphine in humans. Pain 24, 93-116.

Di Rosa M, Giroud JP, Willoughby DA. (1971) Studies on the mediators of the acute inflammatory response induced in rats in different sites by carrageenan and turpentine. J. Pathol. 104, 15-29.

Franzotti EM, Santos CV, Rodrigues HM, Mourao RH, Andrade MR, Antoniolli AR. (2000) Antiinflammatory, analgesic activity and acute toxicity of Sida cordifolia L. (Malva-branca). J. Ethnopharmacol. 72, 273-277.

Griffiths RJ. (1999) Prostaglandins and inflammation. In: Inflammation: Basic Principle and Clinical Correlates, 3rd ed. Gallin JI, Snyderman R. p. 349360, Lippincott Williams and Wilkins Press, Philadelphia.

Hargreaves K, Dubner R, Brown F, Flores C, Joris J. (1988) A new and sensitive method for measuring thermal nociception in cutaneous hyperalgesia. Pain 32, 77-88.

Hudson JB, Graham EA, Harris L, Ashwood-Smith MJ. (1993) The unusual UVA-dependent antiviral properties of the furoisocoumarin, coriandrin. Photochem. Photobiol. 57, 491-496.

Kim DK, Lim JP, Yang JH, Eom DO, Eun JS, Leem KH. (2002) Acetylcholinesterase inhibitors from the roots of Angelica dahurica. Arch. Pharm. Res. 25, 856859.

Kim SH, Kang SS, Kim CM. (1992) Coumarin glycosides from the roots of Angelica dahurica. Arch. Pharm. Res. 15, 73-77.

Kimura Y, Ohminami H, Arichi H, Okuda H, Baba K, Kozawa M. (1982) Effects of various coumarins from roots of Angelica dahurica on actions of adrenaline, ACTH and insulin in fat cells. Planta Med. 45, 183-187.

Kimura Y, Okuda H. (1997) Histamine-release effectors from Angelica dahurica var. dahurica root. J. Nat. Prod. 60, 249-251.

Kofinas C, Chinou I, Loukis A, Harvala C, Roussakis C, Maillard M, Hostettmann K. (1998) Cytotoxic coumarins from the aerial parts of Tordylium apulum and their effects on a non-small-cell bronchial carcinoma line. Planta Med. 64, 174-176.

Kuzel TM, Roenigk HH, Samuelson E, Rosen ST. 
(1992) Suppression of anti-interferon alpha-2a antibody formation in patients with mycosis fungoides by exposure to long-wave $\mathrm{UV}$ radiation in the A range and methosalen ingestion. J. Natl. Cancer Inst. 84, 119-121.

Kwon YS, Kobayashi A, Kajiyama SI, Kawazu K, Kanzaki H, Kim CM. (1997) Antimicrobial constituents of Angelica dahurica. Phytochemistry 44, 887-889.

Light A, Perl E. (2003) Unmyelinated afferent fibers are not only for pain anymore. J. Comp. Neurol. 461, 137-139.

Masferrer JL, Zweifel BS, Manning PT, Hauser SD, Leahy KM, Smith WG, Isakson PC, Seibert K. (1994) Selective inhibition of inducible cyclooxygenase 2 in vivo is anti-inflammatory and nonulcerogenic. Proc. Natl. Acad. Sci. U.S.A. 91, 3228-3232.

Panthong A, Kanjanapothi D, Taesotikul T, Phankummoon A, Panthong K, Reutrakul V. (2004) Anti-inflammatory activity of methanolic extracts from Ventilago harmandiana Pierre. J. Ethnopharmacol. 91, 237-242.
Ryu SY, Kuo NY, Choi HS, Ryu H, Kim TS, Kim KM. (2001) Cnidicin, a coumarin from the root of Angelica koreana, inhibits the degranulation of mast cell and the NO generation in RAW 264.7 cells. Planta Med. 67, 172-174.

Saiki Y, Morinaga K, Okegawa O, Sakai S, Amaya Y. (1971) On the coumarins of the roots of Angelica dahurica Benth. Et Hook. Yakugaku Zasshi 91, 13131317.

Sluka KA, Chandran P. (2002) Enhanced reduction in hyperalgesia by combined administration of clonidine and TENS. Pain 100, 183-190.

Vierck Jr CJ, Cannon RL, Fry G, Maixner WL. (1997) Characteristics of temporal summation of second pain sensations elicited by brief contact of glabrous skin by a preheated thermode. J. Neurophysiol. 78, 992-1002.

Wang NH, Yoshizaki K, Baba K. (2001) Seven new bifuranocoumarins, dahuribirin A-G, from Japanese Bai Zhi. Chem. Pharm. Bull. 49, 1085-1088. 